\title{
infância, cultura visual e educação
}

\author{
adriana hoffmann ${ }^{1}$ \\ universidade federal do estado do rio de janeiro/faperj, brasil \\ orcid id: https://orcid.org/0000-0001-5009-4373 \\ helenice cassino ${ }^{2}$ \\ universidade do estado do rio de janeiro, brasil \\ orcid id: https://orcid.org/0000-0003-3195-5005
}

resumo

Esse artigo traz uma reflexão acerca das relações entre infância, cultura visual e educação. Sabemos que as imagens com as quais convivemos cotidianamente "fabricam nossos modos de ver" e os pesquisadores do campo da Cultura Visual dedicam-se a estudar a respeito desse papel da visualidade no contexto cultural em que vivemos. O intuito é trazer algumas das considerações desses estudiosos para refletir acerca da visualidade no contexto da infância e da educação. Para tanto, o artigo propõe delinear aquilo que se entende por cultura visual e o modo como as concepções de infância produzem e são produzidas por imagens a ela associadas. Discute, ainda, o nascimento do espectador e do produtor de imagens a partir de uma abordagem da filosofia e indaga sobre o papel da educação num contexto de práticas culturais intensamente ligadas aos usos das mídias, no qual crianças crescem cercadas por múltiplas telas, apontando para uma nova literacia visual. Assim, compreendemos que as imagens têm papel fundamental no modo como as crianças dão significados ao mundo e a si mesmas, considerando que os modos de ver e de serem vistas são afetados pelo enquadramento sócio-cultural. Nesse contexto, cabe refletir sobre a maneira com que a cultura visual está presente na escola e quais os desafios que se colocam para produzir modos de ver amplos e criativos para a formação das crianças no campo da Educação.

palavras-chave: infância; cultura visual; educação.

resumen

\section{infancia, cultura visual y educación}

Este artículo presenta una reflexión sobre las relaciones entre la infancia, la cultura visual y la educación. Sabemos que las imágenes con las que convivimos cotidianamente "fabrican nuestros modos de ver" y los investigadores del campo de la cultura visual se dedican a estudiar el papel de la visualidad en el contexto cultural en el que vivimos. La intención es traer algunas de las consideraciones de estos estudiosos para reflexionar acerca de la visualidad en el contexto de la infancia y de la educación. Para esto, el presente artículo propone delinear qué se entiende por cultura visual y el modo como las concepciones de infancia producen y son producidas por imágenes asociadas a ella. Discute también el nacimiento del espectador y del productor de imágenes a partir de un abordaje filosófico e indaga sobre el papel de la educación en un contexto de prácticas culturales intensamente ligadas a los usos de los medios, en las cuales los niños y niñas crecen cercados por múltiples pantallas, apuntando a una nueva literacía visual. Así, comprendemos que las imágenes tienen un papel fundamental en el modo en como los niños y niñas dan significado al mundo y a sí mismos, considerando que los modos de ver $\mathrm{y}$ de ser vistos son afectados por el entorno socio-cultural. En este contexto, cabe

\footnotetext{
${ }^{1}$ E-mail: profadrihoff@gmail.com.

2 E-mail: tucassino@gmail.com
} 
reflexionar sobre la manera como la cultura visual está presente en la escuela y cuales son los desafíos que se colocan para producir modos de ver, amplios y creativos, para la formación de los niños y niñas en el campo de la Educación.

palabras clave: infancia; cultura visual; educación.

\section{childhood, visual culture, and education}

abstract

This article combines thoughts about childhood, visual culture and education. It is known that we live among multiple images that shape the way we see our reality, and researchers in the visual culture field investigate how this role is played out in our culture. The goal is to make some applications those ideas, to think about the relationship between the images and education. This article tries to grasp what visual culture is and in what ways presumptions about childhood generate and are generated by this association. It also discusses the genesis of these presumptions and the images they generate through a philosophical approach, questioning the role of education in a culture tied to the media, and about how children, who are familiar with multiple screens, presage a new visual literacy. We see how images play a fundamental role in the way children give meaning to the world around them and to themselves, in the context of their local culture. Given this context, it is necessary to consider how visual culture is tied to the elementary school, and what challenges confront the generation of wider and more creative ways to approach visual framing in children's education.

key words: childhood; visual culture; education. 
infância, cultura visual e educação

Ver precede as palavras. A criança olha e reconhece, antes mesmo de poder falar. (John Berger)

Ilustrações dos primeiros livros infantis; brinquedos e roupas com cores fortes, diferentes de tempos atrás; estímulos visuais diversos; móbiles pendurados no berço; clipes da turma da Galinha Pintadinha; personagens e cenários do Mundo Bita; filmes como Pets, Minios, Frozen ou Toy Story; livros, acessórios e roupas com a temática de dinossauros; camisetas com os Heróis da Marvel; fotografias nas telas do celular; selfies; brinquedos que materializam personagens, cenários e artefatos dos desenhos em série ou dos filmes infantis; escovas de dente, pasta, lençóis, copos, talheres e pratos adornados com temáticas voltadas para o público infantil; as primeiras representações e desenhos feitos pela criança... Numa rápida listagem, essas são apenas algumas das produções imagéticas presentes no cotidiano infantil envolvendo a visualidade na vida de uma criança de 3 anos. Isso sem falarmos nas visualidades que acompanham as crianças quando crescem nas diferentes faixas etárias. Diante disso é possível questionar: afinal quantas imagens são produzidas e povoam os cotidianos infantis? Quantas dessas imagens constituem visualmente a formação dessa criança? Quantas compartilham com seus pares e com os adultos? O que dizem essas imagens? O que ensinam? Como criam subjetividades, expectativas, desejos? Como alimentam o faz-de-conta e a ludicidade? Que narrativas as acompanham e que outras narrativas propõem? Que concepções de infância estão associadas?

A cultura infantil, demarcada por seus artefatos, produz tanto os modos particulares de estar e de ver o mundo quanto um repertório "estético infantil", no sentido que Maffesoli (1999) dá à palavra estética: compartilhar das mesmas coisas, emoções, valores, dando sentido aos modos de existência. Nesse sentido, há um consenso sobre esses referentes culturais, eles são aceitos e compartilhados em várias instâncias sociais e culturais, e assim passam a ser "naturalizados", como se fossem partes constitutivas da infância contemporânea. (Cunha, 2005, p. 32)

A infância tem sido significada a partir de discursos que criam um imaginário e uma idealização, desconsiderando os diferentes contextos e inserções históricas e culturais. No senso comum a infância está comumente relacionada às 
ideias de inocência e pureza, por um lado, e de incompletude, imaturidade e não racionalidade, por outro, sendo compreendida como um "vir-a-ser", ser que não está "pronto". Nesse sentido, as imagens associadas às crianças e à infância (no singular) são produzidas a partir de uma concepção de infância universal e produzem também modos de vê-la. Por mais que nós, pesquisadores da área, saibamos da limitação dessa compreensão muitas vezes repetida pela mídia e pelo senso comum, as imagens que são feitas em filmes, propagandas e outros produtos destinados para crianças, por vezes trazem de volta e reforçam essa concepção limitadora da infância.

Como aprendemos com Philippe Ariès (1978), o conceito de infância é uma construção social e para essa construção contribuem fatores históricos, sociais, econômicos, culturais. As imagens analisadas pelo autor revelam discursos que construíram ideários de infância ao longo dos tempos e que terminaram por solidificar uma ideia universal, na Modernidade. Mas é também a partir desse estudo que compreendemos que infância é um conceito em constante construção e, portanto, ligado ao seu tempo histórico, à cultura em que é produzida e constituem-se na relação com os diferentes contextos em que estão imersas. Pensar a infância a partir das representações listadas no início deste texto pode sugerir um enorme distanciamento daquela do século XVIII, mas não podemos deixar de entrever o ainda presente sentido de universalização, principalmente considerando as produções da indústria cultural.

Vemos como, ao longo dos anos, mudam as visualidades que envolvem cada faixa etária da infância e que ser criança no século XXI, principalmente nas grandes cidades, já é ser alguém que nasce sob o signo da mídia. Os brinquedos, os filmes, os desenhos animados, os materiais comprados, as brincadeiras, os passeios são todos entremeados pelos produtos e personagens que a mídia direciona para as crianças e passam a compor seus referenciais e suas experiências no e com o mundo.

A partir de nossos estudos temos observado o modo como as produções culturais afetam as experiências infantis. No contexto de um estudo preliminar ${ }^{3}$

\footnotetext{
${ }^{3}$ Estudo desenvolvido no âmbito de um projeto institucional, na Faculdade de Educação da UERJ.
} 
que busca mapear essa relação de crianças pequenas com a cultura visual, temos o relato da mãe de Pedro, criança de 3 anos, que em conversa com a mãe pergunta quando eles irão para Nova York, sem que nunca tenham falado ou ido para tal lugar com o menino. A mãe fica surpresa e ele explica que precisa conhecer o parque onde o Max e o Duque, personagens do filme Pets 1 e Pets 2, vão passear. O menino refere-se ao Central Park, em Nova York, em que os personagens desses filmes vão. O filme citado é muito apreciado por crianças de sua faixa etária. Nova York passa, então, a fazer parte de seu repertório e de suas experiências, mesmo que ele não saiba exatamente onde fica. O menino passa a ter a referência de como é a vida e a atmosfera vivenciada naquela cidade e no Central Park, muito bem "desenhadas" no filme, sem precisar ter estado na cidade, tê-la localizado no mapa, ter visto fotografias ou ter ciência das questões geopolíticas que a atravessam. Certamente essas referências, já incorporadas, serão acessadas se um dia ele viajar para a cidade.

Assim, os repertórios visuais vão se constituindo como cultura e constituindo os sujeitos e com isso sua cultura. Mas, como veremos adiante, não são apenas repertórios imagéticos que conformam a cultura visual, mas tudo o que vem junto com esse repertório, como o momento histórico, as possibilidades tecnológicas, os discursos produzidos, as ideologias e relações de poder. Que imagens estão associadas hoje à infância e que discursos produzem as concepções da infância do século XXI? Que valores são produzidos a partir da produção e fruição dessas imagens?

Parece ser consensual que a invenção da fotografia alterou de forma radical a relação da humanidade com as imagens e com as produções artísticas (Benjamin, 1994; Flusser, 2007, 2009; Berger, 1999; Campos, 2013, Crary, 2012), instaurando novos sensórios, novos modos de apreender o mundo, de se colocar socialmente, de construir memórias, de produzir cultura e informação. Mas cabe considerar, como adverte Portugal (2011, p. 43), quais as circunstâncias e condições que tornaram "viável, pensável, desejável a invenção da fotografia", ou "permitiram o advento da imagem técnica" (Portugal, 2011, p. 41). O autor aponta, assim, para 
regimes de visualidades que estão ligados ao tempo histórico e contextos culturais que abrem caminho para as novas demandas e percepções.

De acordo com Portugal (2011), regimes de visualidades seguem "regras" que apresentam-se imbricadas com a circulação de significados pautados por padrões socioculturais. Citando Gombrich (2007), pergunta porque sujeitos de diferentes idades, diferentes países e tempos históricos representam o mundo visível de maneira distinta. $\mathrm{O}$ autor foge de uma ótica evolucionista e propõe pensar tanto o produtor como o observador de imagens como sujeitos inseridos numa rede social e histórica específica. Basta darmos um passeio pela história da arte para observarmos essas diferenças e concordarmos que não se trata apenas de diferentes técnicas de representação - mais ou menos sofisticadas ou "desenvolvidas" -, mas de uma mudança no olhar. Nesse sentido, entendemos ainda que ao observar uma obra de arte, por exemplo, "O que fazemos daquele minuto pintado quando ele está diante de nossos olhos vai depender daquilo que esperamos da arte, e que, por sua vez, hoje depende de como já vivenciamos o significado de pinturas através de reproduções" (Berger, 1999, p. 33).

Trazendo uma reflexão sobre os novos regimes de visualidades no contexto das mídias, Martín-Barbero afirma que a cultura na modernidade incorporou outras gramáticas "tecnoperceptivas" à cultura oral anterior. Essas gramáticas, num primeiro momento estavam relacionadas às linguagens do rádio e do cinema e depois começam a abranger a visualidade eletrônica da televisão, do vídeo e do computador. Essa visualidade passa, então, a fazer parte "da visualidade cultural, ao mesmo tempo do entorno tecnológico e do novo imaginário, capaz de falar culturalmente - e não só de manipular -, de abrir novos espaços e tempos e uma nova era do sensível." (Martín-Barbero, 2000, p. 84)

O autor expõe a mudança de sensórios profundamente ligadas aos regimes de visualidades que se instauram com as mudanças sociais ao refletir sobre os processos ocorridos na América Latina: "Por mais escandaloso que nos soe, é um fato que as maiorias na América Latina estão se incorporando à modernidade não sob o domínio do livro, mas a partir dos discursos e das narrativas, dos saberes e das linguagens da indústria e da experiência audiovisual." (Martín-Barbero, 2000, 
p. 83 e 84). E segue apontando um descentramento cultural ou uma ruptura com a concepção de cultura baseada na tradição, quando afirma que enquanto a cultura do texto criou uma separação entre adultos e crianças, a televisão abalou uma ordem estabelecida, já que expõe o mundo para as crianças sem depender de um complexo código de acesso, como nos livros.

o que há de verdadeiramente revolucionário na televisão é que ela permite aos mais jovens estar presentes nas interações entre adultos [...] é como se a sociedade inteira tivesse tomado a decisão de autorizar as crianças a assistir as guerras, os enterros, os jogos de sedução, o erotismo, as tramas criminais. A pequena tela expõe os temas e comportamentos que os adultos se esforçaram por ocultar durante séculos (Meyrowitz, 1995, p. 62, apud MartinBarbero, 2000, p. 87).

Trazendo para os dias atuais, entendemos que o acesso aos novos meios digitais expande ainda mais essa interação, constituindo-se também como um campo de produção e atuação infantil.

Ferreira, Rosas e Coutinho (2017) trazem a fala de uma menina de sete anos para contar sobre suas práticas na internet: "A maioria das vezes... não, a maioria, não, TODAS as vezes que eu mexo na internet, que eu vou no computador eu vejo só vídeo... e um pouquinho de jogos". As autoras refletem sobre essas práticas como atualizações da antiga relação com a TV:

E a menina vai listando suas preferências, que incluem em sua maioria canais feitos por YouTubers jovens, falando sobre jogos e temas do cotidiano infanto-juvenil, apresentando desafios, piadinhas e "novelinhas" - que foram apontadas por Lya como sendo o que mais gosta. São produções caseiras, que falam direto a um público específico e nos fazem perguntar se seria essa uma atualização dos modos de ver TV. Será que os canais de vídeo representam hoje o que foi a Televisão para as gerações anteriores? Poderíamos entender que o YouTube é a TV contemporânea, dividida por nichos, feita e compartilhada por pessoas comuns? (Ferreira et. al. 2017, p. 97)

As produções que alcançam as crianças hoje, talvez não sejam mais tão caseiras, como relatado em 2017, e as crianças e jovens que as produzem, algumas vezes tornam-se celebridades, mesmo que provisoriamente, mas certamente apontam semelhanças e também mudanças na relação com os meios e nas possibilidades de criação, e mais ainda nos modos de ver as/das crianças. 
Nossa relação com a imagem vem de longa data, não se caracterizando como aquisição recente, argumenta Ricardo Campos, em livro dedicado a ser uma introdução ao campo de estudos da Cultura Visual, mas assume importância e centralidade nas sociedades contemporâneas a partir do desenvolvimento técnico,

O que é relativamente novo na história da humanidade é a multiplicação de aparatos técnicos que, particularmente desde o aparecimento da fotografia e mais tarde do cinema, no século XIX, vieram transfigurar definitivamente não apenas a ontologia da imagem mas igualmente a nossa vivência visual no mundo. (Campos, 2013, p. 2)

Essa multiplicidade povoa os cotidianos infantis estabelecendo novas formas de lidar com o real. São muitas as telas a partir das quais conhecem o mundo, conversam com parentes, se divertem, aprendem, participam da sociedade ou criam imagens de si, reforçando a pertinência de diálogo com o campo da Cultura Visual. De acordo com Campos, este se constitui como sendo multi e interdisciplinar, abrangendo estudos provenientes de áreas científicas, artísticas e humanísticas, centrados no universo visual para pensar a imagem, o olhar e a visualidade como construções humanas, social e historicamente situadas. O autor posiciona a cultura visual enquanto esfera particular da cultura, produzida e compartilhada por um coletivo de pessoas, calcada em três patamares que se justapõem:

A cultura visual é, em primeiro lugar, um "repositório visual" relacionado com os contextos coletivos particulares, onde linguagens e signos visuais são elaborados e trocados. É, em segundo lugar, um "modo de produzir, apreender e decodificar visualmente a realidade", tendo em consideração a natureza cultural e psicossocial da percepção, da cognição e da representação visual. Por último, é um "sistema" composto por um "aparato tecnológico, político, simbólico e econômico", enquadrado num horizonte sociocultural e histórico mais amplo, com o qual convive, que ajuda a moldar, tal como é por este configurado. (Campos, 2013, p. 53)

Refere-se, portanto, a todos os tipos de artefatos que ajudam o homem a se exprimir no campo do visível ou que estejam ligados ao ato de representação e comunicação. Mas refere-se ainda aos modos de olhar e representar, que são historicamente, socialmente e culturalmente situados, que não são objetivos e que apresentam assimetrias, relações de poder e negociações de sentidos. 
Susana Cunha (2005) observa que os Estudos da Cultura Visual refletem e analisam "como o universo visual (aquilo que se vê) e a visualização (os modos de ver e as tecnologias da visão) estão nos constituindo", indo muito além de simplesmente se ocupar dos artefatos visuais, pois se preocupam "em como as imagens são produzidas, distribuídas e utilizadas socialmente, como uma prática cultural que produz e negocia significados" (Cunha, 2005, p. 43). A autora cita Hernández, para quem

[...] a cultura visual contribui para que os indivíduos fixem as representações sobre si mesmos e sobre o mundo e sobre seus modos de pensar-se. A importância primordial da cultura visual é mediar o processo e como olhamos e como nos olhamos, e contribuir para a produção de mundos. [...] A cultura visual assim entendida cumpre a função de manufaturar as experiências dos seres humanos mediante a produção de significados visuais, sonoros, estéticos etc. Estes significados contribuem para a construção da consciência individual e social pela incorporação dos índices visuais com valor simbólico produzidos por grupos diferentes (o dos artistas seria um deles) nos processos de intercâmbio social. (Hernández, 2000, p. 52 apud Cunha, 2005, p. 43)

Crianças muito pequenas vão entrando em contato com produtos da indústria cultural, mesmo que não os consumam diretamente, na medida em que fazem parte de seu contexto cultural e com eles estabelecerem relações através de imagens publicitárias, de mochilas, roupas e demais acessórios usados por seus pares e que, vez por outra, aparecem na escola ou outros espaços frequentados, constituindo as visualidades formadoras do seu consumo visual. As formas de conhecer, representar e identificar o mundo visível variam de acordo com os regimes de visualidade de cada época. Mas, afinal, como nos tornamos espectadores e produtores de imagens?

\section{o nascimento do espectador ou observador e produtor de imagens}

Fazer uma imagem é pôr o homem no mundo como espectador

(Marie-José Mondzain)

Marie-José Mondzain, filósofa francesa, descreve o momento inaugural do ser humano que se torna espectador a partir de sua própria criação. Ela discorre 
sobre as imagens que nos fazem nascer, através de um relato que pretende contar a história do sujeito que vê. Relato que imagina, "ficção que recolhe das mãos do que foi o primeiro espectador a capacidade de falar e de dizer hoje que gestos fizeram nascer juntos o homem e a imagem e os desafios associados" (Mondzain, 2015, p. 29). Em sua análise, a autora tenta reconhecer aquele que se tornará um dia o espectador do mundo e que também proporcionará que outros sujeitos vejam os mundos que ele vê, trazendo a debate a experiência coletiva da visão que faz nascer esse sujeito.

O Homo spectator, descrito pela autora, assim como o Homo sapiens, produz signos "que lhe permite ouvir e ver, dar a ouvir e dar a ver os movimentos do seu desejo e do seu pensamento" (Mondzain, 2015, p. 15). Esse homem libertou o pensamento do corpo, mas manteve entre estes uma relação de interdependência, pois " [...] é ao pôr o pensamento dentro do corpo e nos gestos desse corpo que o homem que nasce para a humanidade inventa a vida das coisas na ausência destas" (Mondzain, 2015, p. 15). Desta forma, ele vê e se faz ver. De acordo com a autora,

A paleontologia descobre o homem no momento em que este se faz ver, ao dar a ver aquilo que ele quis mostrar-nos. O nascimento do seu olhar está endereçado ao nosso. Só sabemos alguma coisa deste remoto antepassado porque ele deixou marcas. Traços, gestos da sua tecnicidade, do seu engenho, da inteligência no que remeteu. [...] $\mathrm{O}$ autor das imagens deixadas atrás de si para que delas pudéssemos recolher algo relativo à nossa própria definição é o primeiro espectador, isto é, o homem que entra na história que ele pode inscrever, narrar, partilhar. (Mondazin, 2015, p. 16)

As inscrições descobertas na gruta de Chauvet, situada na região francesa de Ardèche, datam de 30 mil anos atrás e são as mais antigas conhecidas até hoje. Elas nos levam a pensar nesse homem que fabrica signos usando a boca e as mãos como ferramentas. De acordo com a filósofa, elas nos fascinam, não pelo reconhecimento de uma sensibilidade gráfica e de uma enorme habilidade ou mesmo pela interpretação dos signos, mas porque estamos diretamente implicados.

Diz-nos alguma coisa porque diz coisas sobre nós. O que está aqui em jogo é o sentido de um gesto e não o significado de um objecto. No silêncio milenar destas imagens, passa-se da virtualidade sonora de uma articulação decisiva do espectador à palavra, logo, 
da situação de espectador àquilo que designou condição humana. [...] Longe dos templos e dos museus, eis-nos nas trevas rupestres onde, há trinta e dois mil anos, uns homens hominizados se designaram a si próprios a espécie encarregada da tarefa singular que lhes incumbia humanizar-se. (Mondzain, 2015, p. 32).

Podemos avistar, junto com a autora, o ato que separa o animal do humano. Portugal (2011) traz perguntas que nos permitem pensar a respeito dessa humanização pela visão: “com o que está relacionado o ato de olhar? Por que se olha? O que se espera ver, ou ainda, o que "existe" nesta "realidade" para se ver? Como se deve agir frente ao que se vê? Como construir as semelhanças ou agrupar visualmente as coisas?" (Portugal, 2011, p. 36). Também nesse sentido, Ricardo Reis (2014, p. 87) questiona:

(...) porque é que isto nos prende a atenção? Porque prestamos mais atenção a umas coisas do que a outras? Vemos com mais atenção ou detalhe aquilo que compreendemos ou o que nos é "estranho"? Que conhecimentos temos de dominar para conseguir ver e interpretar as imagens?

Todas perguntas interessantissimas para pensarmos a relação entre as imagens que vemos e os modos como vemos ou como aprendemos a ver e depois consequentemente a produzir ou a fazer novas imagens a partir do regime de visualidade em que nos formamos.

Para Flusser, filósofo tcheco, as imagens são mediações entre o homem e o seu mundo, que se tornou inacessível. "São ferramentas para superar a alienação humana: elas tinham a função de permitir a ação dentro de um universo no qual o homem não vive mais de forma imediata, mas o enfrenta" (Flusser, 2007, p. 142). Assim, as pinturas rupestres, os vitrais das igrejas, os mapas etc. sempre permitiram a ação a partir de uma decodificação de significados.

Mondzain (2007) sustenta que a inscrição das imagens rupestres são o cenário inaugural que instaurou o homem enquanto espectador numa relação de alteridade. $\mathrm{O}$ homem, na escuridão da caverna, iluminado pela claridade que ele mesmo produziu, entra em contato com o outro eu separado de si e criado a partir de seu gesto. "Ei-lo a estender o braço, apoiado na parede e afastando-se dela num mesmo movimento: a distância de um braço, é esse, de facto, o primeiro 
distanciamento de si em relação ao plano no qual vai compor um elo por via de um contato" (Mondzain, 2007, p. 37).

Oportuno, aqui, lembrar Bakhtin (2003) e os conceitos de exotopia, acabamento e alteridade, que, embora utilizados inicialmente para analisar a produção literária, talvez nos ajudem a pensar sobre essa relação primeira com a imagem. Exotopia, a partir da ideia de um lugar exterior ocupado por aquele que cria e que supõe um olhar que se aproxima e se distancia ao mesmo tempo, está ligado à ideia de alteridade e de acabamento produzido pelo olhar do outro. É o olhar do outro que nos completa, já que a própria condição de viventes supõe o inacabamento, o "por vir". A busca pela totalização faz parte dessa condição, mesmo que o acabamento seja sempre provisório. E nesse sentido poderíamos pensar que o olhar exterior que nos completa pode ser também aquele produzido pela própria imagem. A mão na parede da caverna proporciona uma visão exotópica e alteritária que dá acabamento ao Homo Spectator, descrito por Mondzaim.

Analisando a ideia de autor e autoria em Bakhtin, Faraco (2008) aponta que o pensador entende que "sem deslocamento não há ato criador" (Faraco, 2008, p. 43), pois é preciso que o criador se distancie da própria vida para dar a ela um acabamento, destacando ainda que há uma complexidade no próprio ato de autocontemplação, pois "[...] quando me olho no espelho, em meus olhos olham olhos alheios" (Faraco, 2008, p. 43), reforçando a ideia de um outro eu que me olha de fora.

Para Mondzain, a retração e o recuo criador seriam o momento do distanciamento, que permite ver o outro, uma marca de humanização e uma criticidade do espectador.

Ser um humano é produzir a marca de sua ausência na parede do mundo e constituir-se como sujeito que nunca se verá como objecto entre os outros mas que, vendo o outro, lhe dá a ver o que poderão partilhar; signos, marcas, gestos de acolhimento e de retracção. (Mondzain, 2015, p. 50)

Outro autor que estuda o espectador é Jonathan Crary (2012). O critico de arte e ensaísta prefere o termo observador, no lugar de espectador (este último entendido para ele como aquele que assiste passivamente a um espetáculo). Para 
ele observador é aquele que vê dentro de um determinado conjunto de possibilidades estando inscrito em um sistema de convenções e restrições. Esse modo de entender o observador, pelo autor, já nos aponta a marca da temporalidade em que este focou seus estudos. Crary destaca que não há um sujeito observador prévio a um campo em contínua transformação. É o próprio contexto em mudança que vai conformando esse sujeito que observa. No contexto histórico da visão o que muda é a pluralidade de forças e regras que compõem o campo no qual a percepção ocorre. Diferente de Mondzain, que considera que o espectador antes do século XIX, mostra-se nos primeiros movimentos de olhar e ver o outro pelo modo de comunicar-se pelas marcas da pintura rupestre que leva a identificar a si e ao outro, Crary (2012) já traz um outro contexto de comunicação com a existência dos aparelhos ópticos e surgimento da fotografia e de como esses aparelhos apontam novos lugares de ver e de ser observador.

É claro que quando se fala de um novo observador no século XIX sabe-se que não se pode considerar que houve um observador único daquele século que consiga incluir a imensa diversidade que caracteriza a experiência visual daquele momento, mas Crary (2012) traça a partir dali as condições e forças que definiram e permitiram a formação de um modelo dominante de observador naquele período. Há um conjunto de acontecimentos que tiveram um papel decisivo nos modos pelos quais a visão foi debatida e incorporada em práticas culturais e científicas.

No início do século XIX houve uma radical transformação na concepção do observador a partir de certos aparelhos ópticos. Eles passam a ser lugares de saber e de poder que operam no corpo do indivíduo. A modernidade, de acordo com Crary (2012), é inseparável de uma reconstrução do observador de um lado e, de outro, de uma proliferação de signos e objetos circulantes cujos efeitos coincidem com sua visualidade. Crary (2012) traz Baudrillard, observando que assim como ele outros no século XIX afirmam que junto com o desenvolvimento de novas técnicas industriais emerge um novo tipo de signo. Esses novos "signos" são objetos potencialmente idênticos produzidos em séries indefinidas. Atuam na esfera dos simulacros uns dos outros. 
Nesse novo campo de objetos produzidos em série os de maior impacto foram a fotografia e técnicas para industrializar a criação de imagens. A fotografia converteu-se, segundo Crary (2012), num elemento central na reorganização de todo um território no qual circulam e proliferam signos e imagens, cada um deles efetivamente separado de um referente. Ela, a fotografia, é o elemento de um novo e homogêneo terreno de consumo e circulação no qual se aloja o observador. $O$ "efeito fotografia" no século XIX é um componente crucial da nova economia cultural de valor e de troca. Através dela se estabelecem um novo conjunto de relações abstratas entre indivíduos e coisas impondo essas relações como o real. Um mundo social é representado através dessa visualidade. Por tudo isso Crary afirma que a fotografia foi decisiva para o destino da visualidade do século XIX em diante: “A padronização das imagens visuais no século XIX não deve ser vista simplesmente como parte das novas formas de reprodutibilidade técnica, mas em relação a um processo mais amplo de normatização e sujeição do observador." (Crary, 2012, p. 25, 26).

Houve, segundo Crary, uma autonomização da visão e o tato deixa de ser um componente conceitual da visão. Essa condição histórica reconstruiu o observador sob medida para o consumo "espetacular". Não somente o isolamento empírico da visão permitiu qualificá-la e homogeneizá-la como possibilitou novos objetos da visão (fotografias, mercadorias e o ato da percepção propriamente dito) assumissem uma identidade confusa e abstrata. O estereoscópio é um lugar cultural em que se evidencia de maneira singular essa ruptura entre o que é palpável e o que é visível. Walter Benjamin (1994) mapeou a textura dos eventos e objetos que delinearam o observador do século XIX. Ele viu um observador ambulante formado pela convergência de novos espaços urbanos, novas tecnologias e novas funções econômicas e simbólicas das imagens e dos produtos. Ele esclarece como a modernidade subverte a possibilidade da percepção contemplativa e que jamais há acesso puro ao objeto em sua unicidade pois a visão é sempre múltipla, contígua e sobreposta a outros objetos. Para Benjamin, como comenta Crary, a percepção no contexto da modernidade nunca revelava o mundo 
como presença. O observador para Benjamin era o flaneur, consumidor móvel de uma sucessão de imagens ilusórias semelhantes a mercadorias.

Esse lugar de observador, que é motivo de estudo de Jonathan Crary e que foi pensado também por Walter Benjamin - ambos ao estudarem as mudanças na percepção de todos nós a partir de novos contextos sócioculturais com adventos de novas técnicas para ver - também modifica o nosso lugar de produtores de imagens. Assim, desde que surgiram novas condições de observação da imagem um novo tipo de observador e um novo tipo de produtor começam a experimentar esse novo regime de visualidade.

Ao mesmo tempo em que Crary e os estudiosos da atenção, da percepção e das mudanças no processo de ver percebem mudanças que vão ocorrendo com a chegada de cada novo dispositivo, os estudos da cultura visual apontam que as crianças e jovens estão continuamente percebendo essas "regras" de visualidade e criando a partir delas.

\section{o papel/desafio da cultura visual na educação}

Diante desse contexto qual o desafio para pensar a cultura visual na educação? Uma das propostas dos autores com os quais estamos dialogando é refletir sobre como essa cultura visual está presente na escola, como lidamos com ela e que desafios ela traz para nós. Em texto anterior refletimos acerca dessas demandas atuais na relação com a imagem e trazemos os desafios associados à educação relativos ao modo de lidar com a imagem em profusão nos dias atuais (Hoffmann, 2019). Em diálogo com outros autores aqui, queremos trazer uma visão mais relacionada às possibilidades de criação que podem romper com o excesso de imagens.

Dussel (2009) argumenta que a escola contribuiu para a formação dos sujeitos visuais modernos e a pergunta que parece central, então, é como atua a instituição escolar com as novas visualidades que se estão estruturando nesses tempos, de dentro de uma certa cultura visual?

Ao discorrer sobre a constituição de uma cultura da imagem no campo pedagógico, a autora elenca as muitas formas visuais que a pedagogia moderna assumiu, tais como: 
lições de objetos, armários de exposição nas aulas, museus escolares, mapas, quadros e retratos para colocar nas paredes escolares, estátuas, mobiliário e arquitetura escolar, livros de texto ilustrados, excursões organizadas para ver e aprender, exposições escolares, inclusive os códigos de vestimenta e os regimes de aparências nas escolas (Dussel, 2009, p. 185).

Essas formas, portanto, educaram os modos de ver nos espaços escolares e passaram a estabelecer aquilo que se constituiria como experiência visual. Assim, “o ver se tornou tão importante como a construção de sentido ao redor do que se via" (Dussel, 2009, p. 185). A materialidade do que se via passa a produzir verdades e a representar a verdade, implicando nas leituras de mundo.

Um dos conceitos que vem sendo discutido por autores é esse trabalho da escola na ótica da literacia visual. Ricardo Reis (2014) propõe que literacia visual deve ser compreendida como uma competência cotidiana que é adquirida socialmente, sendo a escola um dos lócus de tal aprendizagem. Ele cita Jonathan Crary para argumentar que a atenção está relacionada a uma concepção subjetiva da visão, além de ressaltar o posicionamento histórico de nosso olhar. Faz sentido, então, compreender que o advento das novas tecnologias levou a um revisão do conceito de literacia, que passa a ser abordado a partir da concepção de multiliteracias ou novas literacias. Tais conceitos englobam tanto a diversidade cultural e linguística das sociedades contemporâneas quanto as capacidades e práticas associadas aos usos dessas tecnologias. O autor aponta que "estas novas literacias, nas quais se inclui com especial destaque a literacia visual, estão em constante mudança tal como as próprias tecnologias, são multifacetadas e a nossa compreensão sobre elas resulta de diferentes pontos de vista coexistentes" (Reis, 2014, p. 88)

A nova visualidade construída na relação com as mídias, como apresenta Martín-Barbero (2000), traz como característica a interpenetração entre oralidade cultural e linguagens audiovisuais e não remete “às ignorâncias, nem aos exotismos do analfabetismo", como defendem muitas vezes os sistemas educativos, "mas a descentramentos culturais que em nossas sociedades estão produzindo os novos regimes de sentir e saber, que passam pela imagem catalisada pela televisão e o computador." (Martín-Barbero, 2000, p. 84). Fazendo 
analogia ao que escreve o autor sobre os modos de recepção dos sujeitos mais jovens, podemos afirmar que estamos diante de uma geração que, mais que na escola, é nos meios audiovisuais, diante das telas, que aprende, faz conexões, experimenta empatia pelas novas tecnologias, se expressa, apreende o mundo e se coloca como participante ativo desse mundo, constrói subjetividades e modos de ver.

O autor cita Vattimo para pensar que hoje o lugar da tecnologia é menos o de domínio da natureza pelas máquinas, e volta-se para o desenvolvimento específico da informação e da comunicação do mundo com imagens. Assim, conclui que "dessa linha é possível a revalorização no campo da educação, já não como mera ilustração da verdade contida na escrita senão como dispositivo de uma produção específica de conhecimento" (Martín-Barbero, 2000, p. 102).

De fato, podemos pensar aqui no conhecimento específico que é produzido pelas tecnologias de comunicação, em especial através das linguagens visuais, e qual seria o lugar da cultura visual na educação diante de um mundo imagético e multitelas. Seria suficiente introduzir as mídias nas escolas para educar as crianças para lidarem com as imagens?

Mirzoeff (2018) traz, em seu trabalho, as dimensões político e éticas dos Estudos Culturais, defendendo que é preciso descolonizar o conhecimento e as mídias, reconhecendo as formas pelas quais elas são colonizadas, e fazer outros usos das mesmas. Ele entende a Cultura Visual como "uma tática para estudar as funções de um mundo abordado por via de imagens de todo o tipo de visualizações", onde o termo visualidade não se presta a designar simplesmente o que é visível, mas representa uma prática discursiva e reforça o poder com autoridade.

Hernandez (2013) considera a cultura visual não somente uma atitude ou metodologia viva mas um ponto de encontro entre o que seria um olhar cultural (visualidade) e as práticas de subjetividades que se vinculam. Esse ponto de encontro permite pesquisar as relações entre os artefatos da cultura visual e aquele que vê (e é visto) e os relatos visuais que, por sua vez, constroem o visualizador. O autor sustenta duas posições: uma em que o relevante nas pedagogias da cultura 
visual não são os objetos, mas sim as relações que mantemos com eles, outra que explora a noção de produtores da cultura visual dos indivíduos, na medida em que não se trata somente de fazer com, mas também de ser com as representações e artefatos da cultura visual. Tomar consciência dessas posições e trabalhar com elas de modo reflexivo na escola não poderia ser um processo de literacia visual?

Isso dialoga com o que observa Dussel (2009), quando argumenta que é preciso compreender a cultura visual para além de um repertório de imagens, mas como

um conjunto de discursos visuais que constroem posições, e que estão inscritos em práticas sociais, estreitamente associados às instituições que nos concedem o "direito de olhar" (entre elas, a escola, que organiza um campo do visível e do invisível, do belo e do feio). (Dussel, 2009, p. 181. Tradução livre)

Voltando à lista, colocada no início do texto, de imagens que povoam os cotidianos infantis, nos indagamos que narrativas são construídas a partir delas e de que forma os contextos educacionais se relacionam com essas narrativas. Que discursos estão embutidos nas tantas imagens? Conscientes de que as imagens fabricam nossos modos de ver e de que vivemos um regime de visualidades que confere valor ao ver e se dar a ver, compreendemos que as crianças vão se constituindo sujeitos nos modos de ver e produzir a partir das conversas que vão realizando com as imagens. A escola pode ser um desses espaços de proposição de reflexões e relações sobre/com e a partir das imagens de forma mais livre e criativa possível.

referências

Ariès, Philippe. A descoberta da infância. In: Ariès, P. História Social da criança e da família. Rio de Janeiro: Guanabara, 1978.

Bakhtin, Mikhail. Estética da criação verbal. 4 ed. São Paulo: Martins Fontes, 2003.

Benjamin, Walter. Obras escolhidas: magia e técnica, arte e política: ensaios sobre literatura e história da cultura. Trad. Sérgio Paulo Rouanet. 7. ed. São Paulo: Brasiliense, 1994.

Berger, John. Modos de ver. Trad. Lúcia Olinto. Rio de Janeiro: Rocco, 1999.

Campos, Ricardo. Introdução à cultura visual: abordagens e metodologias em ciências sociais. Lisboa: Editora Mundos Sociais, 2013.

Caverna de Chauvet. Wikipedia, 2014. Disponível em: <https://pt.wikipedia.org/wiki/Caverna_de_Chauvet> Acesso em: 10, 02, 2020. 
Crary, Jonathan. Técnicas do observador: Visão e modernidade no século XIX. Rio de Janeiro: Contraponto, 2012.

Cunha, Susana Rangel Vieira. Educação e cultura visual: uma trama entre imagens e infância. 2005. Tese (Doutorado em Educação) - Faculdade de Educação, Universidade Federal do Rio Grande do Sul, 2005.

Dussel, Inés. Escuela y cultura de imagem: los nuevos desafíos. In: Nómadas. Colombia, n.30, abril, p. 180-193, 2009.

Faraco, Carlos Alberto. Autor e autoria. In: Brait, Beth (Org.). Bakhtin: conceitos-chave. São Paulo: Contexto, 2008.

Ferreira, Helenice; Rosas, Amanda; Coutinho, Carla Eduarda. Crianças e Youtube: práticas sociais e diferentes formas de viver a infância. In: Anais do Seminário Internacional Infâncias Sul Americanas: crianças nas cidades, políticas e participação. São Paulo: FEUSP, 2017, p.88 - 101.

Flusser, Vilém. O mundo codificado: por uma filosofia do design e da comunicação. Organizado por Rafael Cardoso. Trad. Raquel Abi-Sâmara. São Paulo: Cosac Naify, 2007.

Flusser, Vilém. Filosofia da caixa preta: ensaios para uma futura filosofia da fotografia. Tradução do autor. Rio de Janeiro: Sinergia; Relume Dumará, 2009.

Hoffmann, Adriana. As telas e suas imagens técnicas em aceleração na sociedade: questões para a educação. Revista Educação e Cultura Contemporanea, Rio de Janeiro, vol. 16, n. 43, p. 57-71, 2019.

Hernandez, Fernando. Pesquisar com imagens, pesquisar sobre imagens: revelar aquilo que permanece invisível nas pedagogias da cultura visual. In: Martins, Raimundo, Tourinho, Irene (orgs). Processos E práticas de Pesquisa em Cultura Visual e Educação. Santa Maria: editora da UFSM, 2013.

Martín-Barbero, J.. Novos regimes de visualidade e descentramentos culturais. In: Valter, F., (org.). Batuques, fragmentações e fluxos. Rio de Janeiro: DP\&A, 2000.

Mondzain, Marie-José. Homo spectator: ver, fazer ver. Lisboa: Orfeu Negro, 2015.

Mirzoeff, Nicholas. A teoria não são só palavras numa página, mas também coisas que se fazem. Revista Buala, junho de 2018. Disponível em:, https:/ / www.buala.org/pt/cara-a-cara/a-teoria-nao-sao-so-palavras-numapagina-mas-tambem-coisas-que-se-fazem-entrevista-com-n Acesso 2019. Entrevista concedida a Filipa Cordeiro, FCSH-UNL.

Portugal, Daniel. O realismo entre as tecnologias da imagem e os regimes de visualidades: fotografia, cinema e a "virada imagética" do século XIX. In: Discursos fotográticos. Londrina, v.7, n.11, p.33-54, jul./dez., 2011.

Reis, Ricardo. Um olhar sobre o papel das tecnologias da visão na construção de noções e práticas de literacia visual entre os jovens. In: Revista Lusófona de Educacão. Lisboa, v.26, p.83-102, março, 2014. 